\title{
A Prospective Study to Evaluate Awareness among Healthcare Personnel about Medication Errors in a Tertiary Care Teaching Hospital
}

\author{
Shiv Kumar*, Abhinand Chirayil Ramankutty, Shravan Jayachandran \\ Department of Pharmacy Practice, NET Pharmacy College, Raichur, Karnataka, INDIA.
}

\begin{abstract}
Objectives: To evaluate awareness among health care personnel about medication errors in a tertiary care teaching hospital. Methods: A questionnaire comprising of 17 questions pertaining to different aspects of medication error was prepared. The questionnaire was distributed to 171 healthcare professionals of various departments in the hospital. Respondents of the questionnaire were restricted to one sitting for answering the entire questionnaire and they were not allowed to consult with anyone for the purpose of answering the questions. Data was compiled and analysed. Results: It has been found that $15.78 \%, 32.15 \%, 19.29 \%$ and $30.72 \%$ of respondents were having excellent, good, average and poor knowledge respectively regarding the fundamentals of medication error. Knowledge regarding reporting medication errors was excellent in $26.37 \%$, good in $26.90 \%$, average in $24.56 \%$ and poor in $32.16 \%$ of respondents. About $63.15 \%, 18.12 \%, 7.60 \%$ and $11.09 \%$ of the healthcare professionals were excellent, good, average and poor for recommending or opine about the betterment of the system for reporting medication errors. Among the different healthcare professionals, Pharmacy personnel's are having superior knowledge about the medication error, its reporting system and the suggestion for betterment of its reporting system followed by Nursing and Medical professionals. Conclusion: The present study reveals that all the healthcare professionals are having good to average awareness about medication errors and its reporting system and all the healthcare professionals are strongly suggesting for the betterment of the reporting system.
\end{abstract}

Key words: Awareness, Healthcare professionals, Medication errors, Questionnaire, Reporting system.

\section{INTRODUCTION}

Medication errors are the events related to professional practice, processes involved during prescribing, product labeling, packaging, compounding, dispensing, distribution and administration of drugs and drug-related products. The National Coordinating Council for Medication error (NCCMER) defines a Medication error as being "any preventable event that may cause or lead to inappropriate medication use or patient harm, while the medication is in the control of the healthcare professional, patient or consumer". ${ }^{1}$ They may occur at any time, from the prescription to consumption of the medicines by the patient. ${ }^{2}$

There are different types of medication errors for example prescription errors, dispensing errors, administration errors, monitoring errors, potential errors, compliance errors and clerical errors. ${ }^{3}$ Prescription errors are the biggest contributors with a staggering figure of $70 \%$ of total medication errors. ${ }^{4}$ The leading causes behind other types of medication errors comprise of clogging of healthcare professionals with enormous patients because of alarming shortage of healthcare professionals, especially in developing countries like India, miscommunication amongst the healthcare team. Confusing or misleading drug labeling, packaging, nomenclature of medicines, lack of knowledge about drug therapy also causes medication errors. ${ }^{5}$

In all healthcare systems, medication errors are under reported. This under reporting occurs in all medication use process stages: Prescribing, dispensing and administration. Under reporting of medication errors is
DOI: 10.5530/ijopp.12.4.52

Address for correspondence: Dr. Shiv Kumar, Professor, Department of Pharmacy Practice, NET Pharmacy College, Raichur-584103, Karnataka, INDIA.

Phone no: +91 9035663725 Email Id: shivkumarmatur@ gmail.com

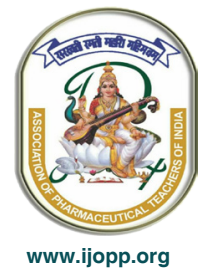


associated with gaps in the knowledge and wrong attitude of healthcare professionals. ${ }^{6}$

Risks for the occurrence of errors exist and need to be examined. Errors can cause deaths and injuries, including in hospitals unfortunately. Within a wide range of studies about errors in the health area, medication errors attract attention. Many researchers are interested in this subject, as they are considered frequent in hospitals, can cause patient damage and increase hospitalization costs. ${ }^{7}$

Thus, in light of the above-mentioned factors, the present study has been undertaken to assess the awareness amongst various healthcare professionals/students regarding medication errors.

\section{MATERIALS AND METHODS}

The study was carried out for a period of two months from February 2018 to April 2018 after the approval from Institutional Ethics Committee of Navodaya Medical College Hospital and Research Center, Raichur.

\section{Study Design}

Type of the Study: Prospective observational study.

Sample Size: 171.

Data collection: By using structured questionnaire.

\section{Inclusion Criteria}

- Doctors, Post Graduate Medical students and Medical interns.

- Pharm D Interns, Final year Pharm D students.

- Nurses, Final year B.Sc. Nursing students.

\section{Exclusion Criteria}

- Those who are unable or unwilling to give informed consent.

The study was carried out in all departments of Navodaya Medical College Hospital and Research Centre, Raichur - a 1000 bedded multi-specialty tertiary care teaching hospital after the approval from the Institutional Ethics Committee.

\section{Questionnaire}

A questionnaire comprising of 17 questions pertaining to medication errors and their management was prepared by referring to previous article. ${ }^{5}$ Questionnaire was provided to healthcare team members as per the inclusion and exclusion criteria in the working hours with their prior permission. The respondents were asked to fill the questionnaire according to their individual view and not allowed to consult any other for opinions on any question. Any clarification needed in understanding the questionnaire was provided. Respondents were instructed to answer the questions of the questionnaire in one sitting, but no time constraint was kept for this purpose. All the completed questionnaires were subjected for analysis.

The highlights of the questionnaire are as follows:

- Every question in the questionnaire is followed by three alternative objective answers viz. "Yes," "No," "No comments"

- Questions in the questionnaire are segregated into three classes for evaluation of awareness in different spheres of concept of medication error. First class is designated as Class " $\mathrm{A}$ " which comprises of seven questions. Questions numbered A1 to A7 of the questionnaire belong to this class and pertain to the fundamental knowledge regarding medication errors and interventions used in prevention and management of medication errors. Every "Yes" response will be given a score of one and every "No" or "No comments" will be scored as zero and cumulative score will be calculated for the whole class of questions.

- Class "B" comprises of questions concerned with the reporting system for medication errors. Question no. B1 to B4 is categorized into this class. Every "No" response for the question no B1 to B3 will be scored as one and every "No comments" or "Yes" will be scored as zero. "Yes" response for the question no. B4 will be scored as one followed by calculation of cumulative score of the class $\mathrm{B}$.

- Class " $C$ " is categorized by making a set of questions related to the capability to give an opinion or recommendations over the escalation of the system for medication errors. Question no C1 to C6 is categorized into this class, for which every "Yes" response will be scored as one, whereas every "No" or "No comments" will be scored as zero.

\section{Questionnaire}

- A1: Do you know about medication error?

- A2: Do you understand the relevance of the term medication error?

- A3: Are you aware of the various categories of medication errors?

- A4: You know that there exist various interventions to prevent medication error?

- A5: Are you aware of the various interventions to prevent medication errors?

- A6: Are you aware how to proceed if medication errors occur? 
- A7: If you noticed a medication error, did you not inform due to fear of any legal consequences?

- B1: After noticing the medication error, did you not inform as you were too busy?

- B2: After noticing the medication error, did you not inform as you did not know whom to inform?

- B3: After noticing a medication error, did you intervene to rectify by using suitable measures?

- B4: Should awareness quantification of medication error particularly to paediatric population be recommended as dosing error is particularly more common in their age group?

- C1: Should there be an improved system in hospitals regarding administration for drug dispensing?

- C2: Do you recommend integrated approach toward training and education about the medication error in medical institute and the general public?

- C3: Are you aware of reporting system and how to report?

- C4: Do you recommend standardized implementation of proper maintenance of data?

- C5: Do you think our institute should from an independent body for reporting medication errors?

- C6: Should proper recommendations to be instituted in the areas of organization, legislation, regulation and resources to improve surveillance and safe use of drugs? Table 1.

\section{RESULTS}

\section{Distribution of healthcare professionals}

A prospective observational study was carried out in a period 2 months. During this period a total of 171 healthcare professionals from different departments were enrolled in the study. Out of 171, 71 were Medical practitioners which includes Doctors, post-graduate students and final years medical students, 60 were nursing staff and final year B.Sc. students and 40 were from Pharmacy Department that include Pharm D interns and final year Pharm D students. The distribution is shown in Figure 1.

\section{Distribution of responses}

Out of 171 respondents, all were responded to all the questions in the questionnaire and they were analysed and categorised the responds into "A", "B" and "C" Classes.

\begin{tabular}{|c|c|c|c|c|c|}
\hline \multirow[t]{2}{*}{ Class } & \multirow{2}{*}{$\begin{array}{c}\text { Total } \\
\text { no. of } \\
\text { questions }\end{array}$} & \multicolumn{4}{|c|}{ Grading Scale } \\
\hline & & Excellent & Good & Average & Poor \\
\hline A & 7 & 7 & 5 or 6 & 4 & $\leq 3$ \\
\hline B & 4 & 4 & 3 & 2 & $\leq 1$ \\
\hline C & 6 & 6 & 5 & 4 & $\leq 3$ \\
\hline
\end{tabular}

The distribution of responses are Depicted in Figure 2.

\section{Scores earned by Medical Personnel}

After obtaining the cumulative scores of different classes of questions it was seen that in Class A, about 2.84\% of medical personnel response were excellent, $15.49 \%$ were good, $22.53 \%$ were average and about $59.14 \%$ were poor. Similarly, in Class B it was seen about $9.85 \%$ were excellent, $25.35 \%$ were good, $25.35 \%$ were average and $39.42 \%$ were poor. In Class $\mathrm{C}$ it was about $63.38 \%$ was excellent, $15.49 \%$ were good, $5.63 \%$ were average and $15.48 \%$ were poor. The scores earned are shown in Table 2.

\section{Scores earned by Nursing Personnel}

From the cumulative scores of different classes of questions, it was seen that in Class A about $13.33 \%$ of nursing personnel's response were excellent, $41.16 \%$ were good, $26.66 \%$ were average and about $18.32 \%$ were poor. Similarly, in Class B it was seen that $14.75 \%$ were excellent, $21.31 \%$ were good, $28.33 \%$ were average and $34.99 \%$ were poor. In Class C it was about $63.15 \%$ was excellent, $26.66 \%$ were good, $11.66 \%$ were average and $8.32 \%$ were poor. The scores earned are shown in Table 3 .

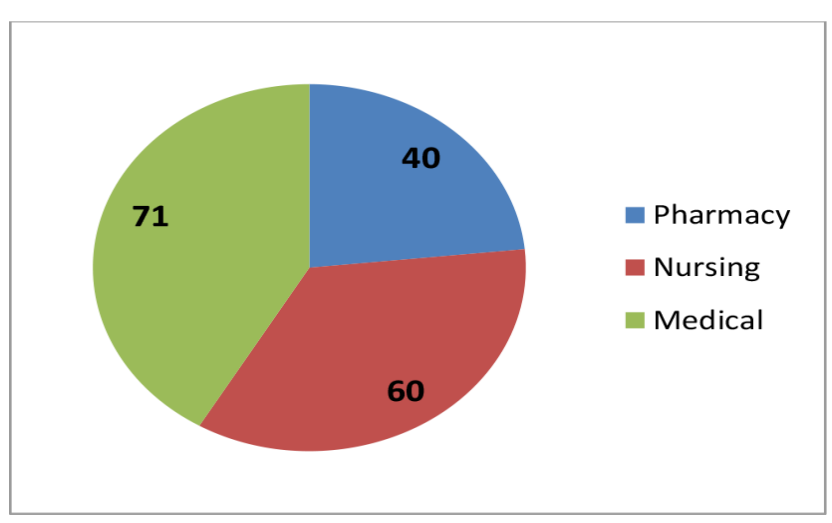

Figure 1: No of healthcare professionals participated in the study.

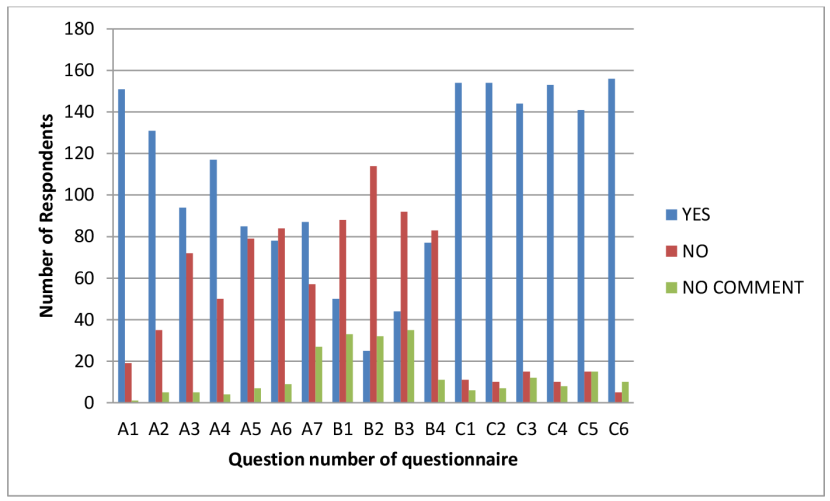

Figure 2: Representation of the relative distribution of responses.

Indian Journal of Pharmacy Practice, Vol 12, Issue 4, Oct-Dec, 2019 


\section{Scores earned by Pharmacy Personnel}

From the cumulative scores of different classes of questions, it was seen that in Class A about $42.5 \%$ of Pharmacy personnel's response were excellent, $47.5 \%$ were good, $2.5 \%$ were average and about $7.5 \%$ were poor. Similarly, in Class B it was seen that $30 \%$ were excellent, $37.5 \%$ were good, $17.5 \%$ were average and $15 \%$ were poor. In Class C it was about $77.5 \%$ was excellent, $10 \%$ were good, $5 \%$ were average and $7.5 \%$ were poor. The scores earned are given in Table 4.

\section{Aggregated Score earned of all the healthcare professionals}

The aggregated score from all the cumulative scores obtained from all the healthcare professionals (Medical, Nursing and Pharmacy) was found to be- Class A about $15.78 \%$ were excellent, $32.15 \%$ were good, $19.29 \%$ were average and about $32.72 \%$ were poor. Similarly, in Class $\mathrm{B}$ it was seen that $16.37 \%$ in excellent, good in $26.90 \%$,

\begin{tabular}{cccc}
\multicolumn{4}{c}{$\begin{array}{c}\text { Table 2: Scores earned by Medical in different classes } \\
\text { of questions. }\end{array}$} \\
$\begin{array}{c}\text { Score } \\
\text { earned }\end{array}$ & $\begin{array}{c}\text { No of } \\
\text { respondents } \\
\text { from class A } \\
\text { Earning score } \\
(\%)\end{array}$ & $\begin{array}{c}\text { No of } \\
\text { respondents } \\
\text { from class B } \\
\text { Earning score } \\
(\%)\end{array}$ & $\begin{array}{c}\text { No of } \\
\text { respondents } \\
\text { from class C } \\
\text { Earning score } \\
(\%)\end{array}$ \\
\hline 7 & $2(2.84)$ & - & - \\
\hline 6 & $6(8.45)$ & - & $45(63.38)$ \\
\hline 5 & $5(7.04)$ & - & $11(15.49)$ \\
4 & $16(22.53)$ & $7(9.85)$ & $4(5.63)$ \\
3 & $17(23.94)$ & $18(25.35)$ & $6(8.45)$ \\
2 & $10(14.08)$ & $18(25.35)$ & $4(5.63)$ \\
1 & $4(5.63)$ & $15(21.12)$ & $0(0)$ \\
0 & $11(15.49)$ & $13(18.30)$ & $1(1.40)$ \\
\hline & & & \\
\hline
\end{tabular}

Table 3: Scores Earned by Nursing in different classes of questions.

\begin{tabular}{cccc}
$\begin{array}{c}\text { Score } \\
\text { earned }\end{array}$ & $\begin{array}{c}\text { No of } \\
\text { respondents } \\
\text { from class A } \\
\text { Earning score } \\
(\%)\end{array}$ & $\begin{array}{c}\text { No of } \\
\text { respondents } \\
\text { from class B } \\
\text { Earning score } \\
(\%)\end{array}$ & $\begin{array}{c}\text { No of } \\
\text { respondents } \\
\text { from class C } \\
\text { Earning score } \\
(\%)\end{array}$ \\
\hline 7 & $8(13.33)$ & - & - \\
6 & $7(11.66)$ & - & $32(53.33)$ \\
5 & $18(29.50)$ & - & $16(26.66)$ \\
4 & $16(26.66)$ & $9(14.75)$ & $7(11.66)$ \\
3 & $5(8.33)$ & $13(21.31)$ & $3(5)$ \\
2 & $3(5)$ & $17(28.33)$ & $1(1.66)$ \\
1 & $2(3.33)$ & $13(21.66)$ & $1(1.66)$ \\
0 & $1(1.66)$ & $8(13.33)$ & $0(0)$ \\
\hline
\end{tabular}

average in $24.56 \%$ and poor in $32.16 \%$ of respondents. In Class C it was about 63.15\% was excellent, $18.12 \%$ were good, $7.60 \%$ were average and $11.09 \%$ were poor. The scores earned are depicted in Table 5.

\section{Comparison of grading earned by different healthcare professionals}

After obtaining the cumulative score, it was seen that the majority of the pharmacy respondents are having a grading Excellent in all 3 classes when compared to other professionals. About $42.5 \%$ respondents in Class A, 30\% respondents in Class B and $77.5 \%$ in Class $\mathrm{C}$ are having Excellent. It is also observed that medical professionals are having more number of Poor Grading, which is about $59.14 \%$ in Class A, 39.42\% in Class B and 34.99\% in Class C. Majority of the Nursing personnel are having a grading of Good to Average. The comparison of the different healthcare professionals are shown in Table 6.

Table 4: Scores earned by Pharmacy in different classes of questions.

\begin{tabular}{cccc}
$\begin{array}{c}\text { Score } \\
\text { earned }\end{array}$ & $\begin{array}{c}\text { No of } \\
\text { respondents } \\
\text { from class A } \\
\text { Earning score } \\
(\%)\end{array}$ & $\begin{array}{c}\text { No of } \\
\text { respondents } \\
\text { from class B } \\
\text { Earning score } \\
(\%)\end{array}$ & $\begin{array}{c}\text { No of } \\
\text { respondents } \\
\text { from class C } \\
\text { Earning score } \\
(\%)\end{array}$ \\
\hline 7 & $17(42.5)$ & - & - \\
\hline 6 & $18(45)$ & - & $31(77.5)$ \\
5 & $1(2.5)$ & - & $4(10)$ \\
4 & $1(2.5)$ & $12(30)$ & $2(5)$ \\
3 & $3(7.5)$ & $15(37.5)$ & $2(5)$ \\
2 & $0(0)$ & $7(17.5)$ & $1(2.5)$ \\
1 & $0(0)$ & $4(10)$ & $0(0)$ \\
0 & $0(0)$ & $2(5)$ & $0(0)$ \\
\hline
\end{tabular}

Table 5: Scores earned by respondents in different classes of questions.

\begin{tabular}{cccc}
$\begin{array}{c}\text { Score } \\
\text { earned }\end{array}$ & $\begin{array}{c}\text { No of } \\
\text { respondents } \\
\text { from class A } \\
\text { Earning score } \\
(\%)\end{array}$ & $\begin{array}{c}\text { No of } \\
\text { respondents } \\
\text { from class B } \\
\text { Earning score } \\
(\%)\end{array}$ & $\begin{array}{c}\text { No of } \\
\text { respondents } \\
\text { from class C } \\
\text { Earning score } \\
(\%)\end{array}$ \\
\hline 7 & $27(15.78)$ & - & - \\
6 & $31(18.12)$ & - & $108(63.15)$ \\
5 & $24(14.03)$ & - & $31(18.12)$ \\
4 & $33(19.29)$ & $28(16.37)$ & $13(7.60)$ \\
3 & $25(14.61)$ & $46(26.90)$ & $11(6.43)$ \\
2 & $13(7.60)$ & $42(24.56)$ & $6(350)$ \\
1 & $6(3.50)$ & $32(18.71)$ & $1(0.58)$ \\
0 & $12(7.01)$ & $23(13.45)$ & $1(0.58)$ \\
\hline
\end{tabular}


Table 6: Comparison of grading earned by different healthcare professionals.

\begin{tabular}{cccccc} 
Class & Healthcare Profession & \multicolumn{4}{c}{ Grading } \\
\cline { 3 - 5 } & & Excellent & Good & Average & Poor \\
\hline \multirow{3}{*}{ Class A } & Medical Personnel & $2.84 \%$ & $15.49 \%$ & $22.53 \%$ & $59.14 \%$ \\
& Nursing Personnel & $13.33 \%$ & $41.16 \%$ & $26.66 \%$ & $18.32 \%$ \\
& Pharmacy Personnel & $42.50 \%$ & $47.5 \%$ & $2.5 \%$ & $7.5 \%$ \\
\multirow{2}{*}{ Class B } & Medical Personnel & $9.85 \%$ & $25.35 \%$ & $25.35 \%$ & $39.42 \%$ \\
& Nursing Personnel & $14.75 \%$ & $21.31 \%$ & $28.33 \%$ & $34.99 \%$ \\
& Pharmacy Personnel & $30 \%$ & $37.50 \%$ & $17.50 \%$ & $15 \%$ \\
& Medical Personnel & $63.38 \%$ & $15.48 \%$ & $5.63 \%$ & $15.49 \%$ \\
& Nursing Personnel & $63.15 \%$ & $26.66 \%$ & $11.66 \%$ & $8.32 \%$ \\
& Pharmacy Personnel & $77.50 \%$ & $10 \%$ & $5 \%$ & $7.50 \%$ \\
\hline
\end{tabular}

\section{DISCUSSION}

The prevalence of medication errors is high even in developed countries, despite the management of medication use process using a computerized system and robotic dispensing facilities, print-out prescriptions, hospital formularies and specialized clinical pharmacists. ${ }^{6}$ Developing countries are still lacking good health-care systems and are falling short of adequate number of health-care personnel after each patient. Therefore, there are high probabilities of occurrence of medication errors across the entire spectrum of prescribing, dispensing and administering. ${ }^{5}$ Medication errors are not individual generated rather they are system generated. Also, reporting "near misses" may contribute a lot for the future corrective measures to safeguard the patients. ${ }^{8}$

The present study has been undertaken to assess the awareness amongst various healthcare professionals/ students regarding medication errors by involving 171 respondents of which, 71 respondents were medical personnel followed by nursing (60) and Pharmacy (40).

The study reveals that $67.22 \%$ respondents are having average or above average basic knowledge regarding medication errors whereas $67.83 \%$ respondents are having knowledge regarding non-existence of reporting system for medication error in India. These figures suggest that health-care professionals are aware about the medication error and therefore establishment of reporting system may help in combating the problem of medication errors. Further, the figures obtained are in agreement with a study carried out by Sewal RK et al. ${ }^{5}$ who evaluated the awareness about medication errors amongst health-care personnel representing North, East, West Regions of India.

Establishment of medication error reporting system does not meet the objective of reducing the medication error. There is a challenge of eliminating the under reporting of errors even after the establishment of reporting system. ${ }^{9}$ There are numerous factors responsible for the under reporting of medication errors which include fear of adverse consequences, tarnishing of reputation, overburden of work..$^{10,11}$

It was seen that the majority of the respondents in grading Excellent are of pharmacy personnel in all 3 classes when compared to other professionals. It was about $42.5 \%$ respondents in Class A, 30\% respondents in Class B and $77.5 \%$ in Class C are having Excellent. It was also observed that medical professionals are having more number of Poor Grading, which was about 59.14\% in Class A, 39.42\% in Class B and 15.49\% in Class C. Majority of the Nursing personnel are having a grading of Good in Class A (41.16\%) and Class C (26.66\%) and Poor in Class B (34.99\%).

\section{CONCLUSION}

The present study reveals that all the healthcare professionals are having good to average awareness about medication errors and its reporting system and all the healthcare professionals are strongly suggesting for the betterment of the reporting system. Among the 3 healthcare professionals, Pharmacy personnel's are having superior knowledge about the medication error, its reporting system and the suggestion for betterment of its reporting system followed by Nursing and Medical professionals.

Conclusively, unbiased assessment of awareness among healthcare professionals may pivot the pathway to the establishment of a system which will help in monitoring and controlling the occurrence of medication error.

\section{ACKNOWLEDGEMENT}

It is a pleasure and privilege to express our deep sense of thanks and indebtedness to the Dr. H Doddayya, 
Principal, NET Pharmacy College, Raichur and Dr. Ashok Mahendrakar, Medical Superintendent, NMCH and RC for giving the consent and facilities to carry out this work.

\section{CONFLICT OF INTEREST}

The authors have no conflict of interest.

\section{Ethical approval}

The study was approved by the Institutional Ethics Committee, Navodaya Medical College Hospital and Research Centre, Raichur.

\section{SUMMARY}

- The present study was conducted to assess the awareness among different healthcare personnel about medication error and its reporting system.

- About 171 different healthcare personnels were enrolled in which 71 were medical personnel, 60 were nursing personnel and 40 were pharmacy personnel.

- A questionnaire comprising of 17 questions was used to assess the awareness about medication errors.

- The questions were segregated into 3 classes - A, B and C. Class A questions pertains to fundamental knowledge about medication errors and interventions used in management of them. Class B questions are concerned with reporting systems of medication errors. Class C questions are related to capability to give recommendation over escalation of medication error reporting system.

- The scores for each class of questions were graded into Excellent, Good, Average and Poor.

- The study reveals that $67.22 \%$ respondents are having average or above average basic knowledge regarding medication errors whereas $67.83 \%$ respondents are having knowledge regarding non-existence of reporting system for medication error in India.

- It was seen that the majority of the respondents in grading Excellent are of pharmacy personnel in all 3 classes when compared to other professionals. It was about $42.5 \%$ respondents in Class A, 30\% respondents in Class B and $77.5 \%$ in Class C.

- It was also observed that medical personnel are having more number of Poor Grading, which was about $59.14 \%$ in Class A, $39.42 \%$ in Class B and $15.49 \%$ in Class C.

- Also majority of the Nursing personnel are having a grading of Good in Class A (41.16\%) and Class C $(26.66 \%)$ and Poor in Class B (34.99\%).

\section{REFERENCES}

1. Jaykare SC, Motghare VM, Padwal SL, Deshmukh VS, Patil JR, Pise HN, et al. Medication errors, what healthcare providers think? A knowledge, attitude and practice survey. Asian J Pharm Clin Res. 2013;6(3):57-9.

2. American Society of Hospital Pharmacists. ASHP guidelines on preventing medication errors in hospitals. Am J Hosp Pharm. 1993;50:305-14.

3. Velo GP, Minuz P. Medication errors: Prescribing faults and prescription errors. Br J Clin Pharmacol. 2009;67(6):624-8.

4. Kuo GM, Phillips RL, Graham D, Hickner JM. Medication errors reported by us family physicians and their office staff. Qual Saf Health Care. 2008;17(4):286-90.

5. Sewal RK, Singh PK, Prakash A, Kumar B, Medhi B. A prospective study to evaluate awareness about medication errors amongst health-care personnel representing North, East, West Regions of India. Int J App Basic Med Res. 2014;4(1):43-6.

6. Abdel LMM. Knowledge of healthcare professionals about medication errors in hospitals. J Basic Clin Pharm. 2016;7(3):87-9.

7. Bohomol E, Ramos LH. Perceptions about medication errors: Analysis of answers by the nursing team. Rev Lat Am Enfermagem. 2006;14(6):887-92.

8. Terzibanjana AR, Laaksonenb $R$, Weissb M, Airaksinena M, Wulijic T. Netherlands: International Pharmaceutical Federation. 2008. Medication Error Reporting Systems - Lessons Learnt: Executive Summary of The Findings. Available from:http://www.fip.org/files/fip/Patient\%20Safety/Medication\%20 Error\%20Reporting\%20-\%20Lessons\%20Learnt2008.pdf

9. Leape LL. Error in medicine. JAMA. 1994;272(23):1851-7.

10. Osborne J, Blais K, Hayes JS. Nurses' perceptions: When is it a medication error?. J Nurs Adm. 1999;29(4):33-8.

11. Uribe CL, Schweikhart SB, Pathak DS, Dow M, Marsh GB. Perceived barriers to medical-error reporting: An exploratory investigation. J Healthc Manag. 2002;47(4):263-79. 